\title{
Emotional Perseveration: An Update on Prefrontal-Amygdala Interactions in Fear Extinction
}

\author{
Francisco Sotres-Bayon, ${ }^{1}$ David E.A. Bush, and Joseph E. LeDoux \\ Center for Neural Science, New York University, New York, New York 10003-6621, USA
}

\begin{abstract}
Fear extinction refers to the ability to adapt as situations change by learning to suppress a previously learned fear. This process involves a gradual reduction in the capacity of a fear-conditioned stimulus to elicit fear by presenting the conditioned stimulus repeatedly on its own. Fear extinction is context-dependent and is generally considered to involve the establishment of inhibitory control of the prefrontal cortex over amygdala-based fear processes. In this paper, we review research progress on the neural basis of fear extinction with a focus on the role of the amygdala and the prefrontal cortex. We evaluate two competing hypotheses for how the medial prefrontal cortex inhibits amygdala output. In addition, we present new findings showing that lesions of the basal amygdala do not affect fear extinction. Based on this result, we propose an updated model for integrating hippocampal-based contextual information with prefrontal-amygdala circuitry.
\end{abstract}

In the presence of threatening or painful stimuli, the brain learns and stores information about other stimuli present so that these can be used as warning signals in future situations. However, the things that are dangerous today are not necessarily always going to be harmful, and it is important to be able to adapt as situations change.

Pavlovian fear conditioning is a behavioral procedure that can be used to study the brain mechanisms underlying the acquisition and storage of information about danger, as well as the mechanisms underlying adaptive responses as situations change (e.g., Fanselow 1998; LeDoux 2000; Davis and Whalen 2001; Maren 2001). In this procedure, an emotionally neutral stimulus, such as a tone, is paired with an aversive event, the unconditioned stimulus (US), typically an electric shock. The pairing of the tone and US results in the transformation of the previously neutral stimulus into an emotionally potent conditioned stimulus (CS) capable of eliciting a complex pattern of physiological adjustments that constitute a fear or defense response, including defensive behavior (freezing), and supporting changes in autonomic and endocrine activity. If the CS is subsequently presented repeatedly in the absence of the US, it gradually loses the ability to elicit these fear-related responses. This weakening of the ability to elicit a conditioned response is referred to as extinction.

Research over the past few decades has identified neural systems that underlie the acquisition and storage of the CS-US association and the expression of fear responses to the CS (for reviews, see LeDoux 2000; Davis and Whalen 2001; Maren 2001). Acquisition and storage involve circuits that transmit the CS and US to the lateral amygdala (LA). Expression of conditioned fear involves CS transmission to the LA, connections from the LA to the central amygdala (CE), either directly or by way of intraamygdala connections (see below), and then output connections from the $\mathrm{CE}$ to various regions that control specific conditioned responses (behavioral, autonomic, endocrine).

Progress has also been made in understanding the extinction of conditioned fear when the CS is repeatedly presented in the absence of the US. Contrary to common wisdom, extinction is not equivalent to forgetting but instead represents new learning-learning that the CS no longer reliably predicts the US (Ber-

\footnotetext{
'Corresponding author.

E-MAIL fsotres@cns.nyu.edu; FAX (212) 995-4704.

Article and publication are at http://www.learnmem.org/cgi/doi/10.1101/ Im.79504.
}

man and Dudai 2001; Bouton 2002; Myers and Davis 2002). The neural basis of fear extinction is believed to involve connections between the medial prefrontal cortex (mPFC) and the amygdala (Morgan et al. 1993; Morgan and LeDoux 1995; LeDoux 1996, 2000; Garcia et al. 1999; Quirk et al. 2000; LeDoux and Gorman 2001; Garcia 2002; Grace and Rosenkranz 2002; Herry and Garcia 2002; Milad and Quirk 2002; Myers and Davis 2002; Paré et al. 2004). However, the nature of involvement of the mPFC and the amygdala and their interactions in extinction of fear are still poorly understood.

Current interest in the role of the mPFC in extinction of fear began when Morgan et al. (1993) reported that rats with lesions of the $\mathrm{mPFC}$ had an increased resistance to extinction. Damage to the prefrontal cortex had long been known to produce changes in emotionality as well as perseverative responses in certain cognitive tasks (Nauta 1971; Luria 1973a,b; Goldman-Rakic 1987). Integrating these findings with their observations on fear extinction, Morgan et al. (1993) proposed that the resistance to extinction following mPFC damage represented perseverative tendencies in the emotional domain. They further proposed that connections between the mPFC and amygdala normally allow the organism to adjust its emotional behavior when environmental circumstances change, and that some alteration in this circuitry, causing a loss of prefrontal control of the amygdala, might underlie the inability of persons with anxiety disorders to regulate their emotions.

Over the past decade, considerable research has been conducted on the role of the mPFC and the amygdala, and their interactions in fear extinction. This special issue of Learning \& Memory features many of the key findings. In this article, we review the original impetus for pursing the role of the $\mathrm{mPFC}$, and survey some of the findings that have come since. We also review parallel research on the role of the amygdala in extinction, and present some new findings regarding amygdala-mPFC interactions.

\section{Prefrontal Cortex Contributions to Fear Extinction}

To assess the prefrontal cortex contributions to fear extinction, we first briefly review its general anatomical organization in mammals. Next, we return to the original findings that motivated interest in the role of the mPFC in extinction of conditioned fear, and then we consider the evidence that has subse- 
quently accumulated, which has both confirmed and refined our understanding of mPFC involvement in the regulation of fear.

\section{Anatomical Organization of the Prefrontal Cortex in Mammals}

The prefrontal cortex consists of several functionally distinct subregions (Posner 1992; Seamans et al. 1995; Robbins 1996; Bechara et al. 1998; Botvinick et al. 1999; Carter et al. 1999; Owen et al. 1999; Smith and Jonides 1999; Muller et al. 2002; Heidbreder and Groenewegen 2003). In humans and other primates, these include the lateral prefrontal cortex, orbital frontal cortex, and mPFC. The lateral prefrontal cortex, especially the dorsolateral region, is involved in working memory and executive control functions (Goldman-Rakic 1995; Owen et al. 1999; Smith and Jonides 1999; D'Esposito et al. 2000; Levy and Goldman-Rakic 2000; Miller and Cohen 2001; Curtis and D'Esposito 2003). The orbital frontal cortex is involved in reward, motivation, and emotional decision making (Damasio 1990; Robbins 1996; Rolls 1996, 2000; Rogers et al. 1999; Bechara et al. 2000; Berns et al. 2001). The mPFC itself has several divisions, including the anterior cingulate cortex and several more ventral areas that include the infralimbic (IL) and prelimbic (PL) cortices, and the medial frontal gyrus. The anterior cingulate is divided into two parts, a dorsal part involved in attention and cognitive control and a more ventral part involved in emotional regulation (Bush et al. 2000; Cohen et al. 2000). The functional contribution of the ventral mPFC (vmPFC: regions below the ventral anterior cingulate, and involving the IL and PL, among other regions) in humans is less clear.

In non-primate species, the prefrontal cortex is poorly developed. Indeed, it is generally accepted that the lateral prefrontal cortex is a unique primate specialization (Povinelli and Preuss 1995; Preuss 1995). However, the orbital frontal cortex and various other mPFC regions (anterior cingulate, IL, PL) are present in rodents and other non-primate mammals (Uylings et al. 2003). The role of the mPFC areas in extinction of fear has been examined, and is reviewed below.

\section{Evidence Implicating the mPFC in Fear Extinction}

Research on the neural basis of fear extinction was stimulated by two studies in the late 1980s showing that damage to sensory processing regions of the cortex (auditory or visual) leads to increased resistance to extinction (LeDoux et al. 1989; Teich et al. 1989). In their study, LeDoux et al. (1989) proposed that the sensory cortex was not the locus of extinction, but instead was a necessary way-station to other regions, possibly the hippocampus or mPFC. This hypothesis was based on a variety of disparate findings that implicated the latter two regions in the extinction of one or more behavioral tasks, although at the time little work had been done on the neural basis of extinction using fearconditioning tasks.

Morgan et al. (1993) then examined the effects of damage to the mPFC on fear extinction of rats, and found that many more days of exposure to the CS in the absence of the US were required in order for CS-elicited fear responses to be reduced to pretraining levels. Follow-up studies systematically examined the effects of damage to the dorsal mPFC (anterior cingulate cortex) and vmPFC (Morgan and LeDoux 1995). Lesions circumscribed to the vmPFC had no effect on the amount of fear behavior (freezing) expressed on a given trial but greatly increased the number of CS-alone trials required to extinguish the behavior. Damage to the dorsal mPFC led to an increased resistance to extinction but also resulted in an increased amount of freezing behavior expressed on each trial (Morgan and LeDoux 1995). With the dorsal mPFC lesions, it was unclear if the effect on extinction was really due to increased resistance to extinction, because the effect could also be explained by the overall increase in the expression of conditioned fear. In contrast, damage to the vmPFC selectively impaired extinction over days without increasing the expression of fear within trials, and therefore most subsequent research on the role of the mPFC in extinction has focused on the vmPFC.

A later study addressing the role of the vmPFC in extinction failed to replicate Morgan's findings (Gewirtz et al. 1997). However, this study used fear-potentiated startle, a training and testing paradigm that differs significantly from the task described so far, which we will refer to as simple fear conditioning. Differences between the training task (e.g., partial vs. continuous reinforcement), testing task, or other procedural differences, may account, at least in part, for the discrepancy between the findings. Although Gewirtz et al. (1997) made a strong effort to make training and testing conditions similar to Morgan et al. (1993), several methodological differences still remained. Indeed, studies from several other research groups using similar simple fearconditioning tasks, rather than potentiated startle, have implicated the mPFC in fear extinction. For example, Morrow et al. (1999) showed that lesions to the dopaminergic inputs to the mPFC caused a deficit in fear extinction. Quirk and colleagues (Lebron et al. 2003) directly replicated the effects of vmPFC lesions on the extinction of freezing over days reported by Morgan et al. (1993). Furthermore, Quirk and collaborators (Quirk et al. 2000) showed that lesions of the IL subregion of the vmPFC impair the retrieval of extinction learning (from a previous day), but not its expression or short-term processing (gradual extinction that occurs within a single session of CS-alone presentations), suggesting a specific role for the IL in the retrieval of extinction. Particularly dramatic is the finding that pairing the tone CS with brief IL stimulation reduces freezing in rats, suggesting that IL stimulation is sufficient to simulate extinction learning (Milad and Quirk 2002; Milad et al. 2004).

Results from electrophysiological and imaging studies in rats and humans provide further support for the view that functional changes in $\mathrm{mPFC}$ are associated with the retrieval of extinction training. Milad and Quirk (2002) found that IL neurons respond to CS exposure on the day following extinction training, suggesting that these cells do not respond to the CS during fear conditioning or during extinction training, but instead specifically respond when the memory of extinction training is retrieved. Similarly, Garcia and colleagues observed that induction of synaptic plasticity by giving LTP-inducing high frequency stimulation of mediodorsal thalamic inputs to mPFC is associated with the maintenance of extinction, but not its acquisition (Herry et al. 1999; Herry and Garcia 2002, 2003; for review, see Garcia 2002). Thus, findings from both the Quirk and Garcia groups suggest that the mPFC is involved in the retrieval (or consolidation) of extinction as opposed to the initial learning of the extinction. In a different set of studies, Barrett et al. (2003) mapped metabolic neural activity after extinction using a radiolabeled glucose analog and confirmed that elevated mPFC activity is evident after the retrieval of prior extinction learning. Interestingly, another related experiment waits to be performed: No one has yet examined brain metabolism or immediate early gene expression in animals during extinction acquisition. This would give a better understanding of the dynamic interaction between specific loci of the different brain areas thought to be involved in fear extinction. Finally, consonant with the nonhuman animal research, PET and fMRI imaging studies have shown that areas of the mPFC in humans are implicated in fear extinction (Hugdahl et al. 1995; Phelps et al. 2004). Results from human studies of fear extinction are discussed further below, with an emphasis on clinical implications of mPFC-amygdala interactions.

Overall, throughout this literature the predominant view has been that extinction involves a process by which neural ac-

\section{Learning \& Memory \\ www.learnmem.org}


tivity in the mPFC comes to regulate the amygdala-mediated expression of conditioned fear responses. However, the amygdala itself has also been implicated in fear extinction, as discussed next.

\section{Amygdala Contributions to Fear Extinction}

The fact that the mPFC plays a key role in extinction does not mean that it alone is involved in this process. An important question concerns whether the amygdala contributes to fear extinction. Because damage to the amygdala prevents the acquisition and expression of fear conditioning (LeDoux 2000; Davis and Whalen 2001; Maren 2001), the use of lesions in evaluating amygdala contributions for fear extinction has been problematic. We return to this issue below, but for now, because amygdala regions have unique cytoarchitectonic and connectional characteristics (Pitkänen et al. 2000a, 2003), we first review the organization of some of the relevant amygdala areas, including LA, basal nucleus (B), CE, and the intercalated cell masses (ITC). Then we review functional evidence that implicates the amygdala in fear extinction.

\section{Anatomical Organization of the Amygdala}

At the beginning of this manuscript, we noted that the two main regions of the amygdala involved in fear conditioning are the LA (the sensory input region that receives the CS and US) and the CE (the output region that controls the expression of fear responses). There are direct connections between the LA and CE, but in addition, the LA communicates with the CE by way of intermediate connections within the amygdala (Paré et al. 1995, 2003; Pitkänen et al. 1997; Savander et al. 1997). Specifically, the LA projects to the $\mathrm{B}$, accessory basal, and the ITC, and each of these projects to the $\mathrm{CE}$. In addition, the $\mathrm{B}$ projects to the ITC, providing another link to the CE.

The LA and B are composed of two major types of neurons: glutamate-containing spiny multipolar cells (pyramidal-like cells) and aspiny $\gamma$-aminobutyric acid (GABA) immunoreactive cells (Pitkänen 2001; Rainnie 2003). The GABAergic cells are interneurons and constitute the main source of local inhibition, whereas the excitatory pyramidal-like cells give rise to connections with other amygdala regions, such as the $\mathrm{CE}$, in addition to initiating collateral fibers that terminate locally on excitatory and inhibitory cells (McDonald 1985; McDonald and Augustine 1993; Smith and Paré 1994; Paré et al. 1995; McDonald and Betette 2001; Li et al. 2002). ITC cells, in contrast, are all small, interconnected, densely packed spiny inhibitory GABAergic neurons that receive connections from the LA and $\mathrm{B}$ and project to the CE (McDonald and Augustine 1993; Paré and Smith 1993, 1998; Ghashghaei and Barbas 2002; Royer and Paré 2002). Thus, the connections from the LA and $\mathrm{B}$ to the $\mathrm{CE}$, and from the LA and $\mathrm{B}$ to the ITC are mostly excitatory, and the connections from the ITC to the CE are mostly inhibitory.

It is important to note that the connections from the LA, B, and ITC to the CE terminate on different groups within the CE. The LA sends fibers to the lateral capsular portion of the CE, whereas the ITC sends projections to the medial part of the CE (Quirk et al. 2003; Paré et al. 2004). The B sends projections to both CE subdivisions (Krettek and Price 1978; Paré et al. 1995, 2003; Collins and Paré 1999; Royer et al. 1999). This is significant because the medial part of the CE constitutes the main output pathway for amygdala projections that control behavioral and autonomic responses, suggesting that the $\mathrm{B}$ may gate the efficacy of LA inputs to brainstem-projecting CE cells (Paré et al. 2003). Interestingly, anatomical (van Groen and Wyss 1990; McDonald and Mascagni 1997; McDonald 1998; Pitkänen et al. 2000b) and electrophysiological (Colino and Fernandez de Molina 1986a,b; Maren and Fanselow 1995; Ishikawa and Nakamura 2003) studies suggest that the B is a main locus for hippocampal afferents to the amygdala. However, damage to the $\mathrm{B}$ does not prevent fear conditioning (Amorapanth et al. 2000; but see Goosens and Maren 2001; Nader et al. 2001), suggesting that the direct pathway from the LA to the CE, or the connection from the LA to the ITC to the CE is sufficient. It is possible that although the B is not necessary for fear conditioning, it normally contributes when still intact.

\section{Evidence Implicating the Amygdala in Fear Extinction}

Tone-elicited neural activity in LA neurons increases following pairing of the tone CS with a US (Quirk et al. 1995; Rogan et al. 1997; Collins and Paré 2000; Repa et al. 2001; Blair et al. 2003; Goosens et al. 2003). During extinction, the responses of many of these cells return to pretraining levels (Quirk et al. 1995; Repa et al. 2001; Hobin et al. 2003). However, recently Repa et al. (2001) also found a population of cells in which CS-elicited activity remained elevated throughout extinction training. Such activity is consistent with the idea that extinction does not erase the original CS-US association (Rescorla 2001; Bouton 2002) and that extinguished fears can be recovered by various manipulations by tapping into this extinction-resistant activity (Repa et al. 2001). In addition, fMRI studies in humans have confirmed that amygdala activation occurs not only during the acquisition, but also during the extinction of conditioned fear (Phelps et al. 2004).

It is widely accepted that NMDA receptors contribute to the synaptic plasticity that underlies learning and memory in a variety of brain systems (see Morris 1989; Bliss and Collingridge 1993; Martin et al. 2000), including the amygdala systems underlying fear conditioning (e.g., LeDoux 2000; Blair et al. 2001; Maren 2001; Walker and Davis 2002). Given that extinction is believed to be a form of learning, one in which the learned ability of the CS to elicit fear becomes inhibited, Davis and colleagues infused the NMDA receptor antagonist D,L-2-amino-5-phosphonopentanoid acid (AP5) into the LA and B prior to extinction training and found that the extinction of conditioned fear was disrupted (Falls et al. 1992). Furthermore, inhibition of mitogenactivated protein kinase (MAPK), a protein that contributes to long-term stabilization and storage of fear memories in the amygdala and other systems (Atkins et al. 1998; Schafe and LeDoux 2000; Schafe et al. 2000), and that can putatively be activated by calcium entry into the postsynaptic cells during the opening of NMDA receptors, also blocked extinction (Lu et al. 2001). Finally, intra-amygdala infusion of an NMDA agonist, D-cycloserine, facilitates extinction of fear (Walker et al. 2002; Ledgerwood et al. 2003). Taken together, these findings indicate that neural activity in the amygdala that leads to NMDA-dependent plasticity plays an important role in extinction (Davis 2002; Davis and Myers 2002; Walker and Davis 2002; Davis et al. 2003).

Nevertheless, the precise role of NMDA-dependent plasticity within the amygdala in extinction remains to be clarified. The studies described above used the fear-potentiated startle paradigm, which, as noted earlier, differs in some respects from simple fear conditioning. For example, infusion of AP5 into the LA and B prior to training disrupts learning, but infusion prior to testing has no effect on the expression of fear responses in the fear-potentiated startle paradigm (Miserendino et al. 1990; Walker and Davis 2000). With simple fear conditioning, however, infusion of AP5 into the LA and B prior to training disrupts learning, and this treatment also affects the expression of fear responses when infused before testing (Maren et al. 1996; Lee and Kim 1998; Rodrigues et al. 2001). This result is consistent with the finding that AP5 has a significant effect on synaptic transmission in the LA (Li et al. 1995, 1996; LeDoux 1996; Weisskopf et al. 1999), and thus it is difficult to conclude that the effects of 
AP5 on simple fear conditioning are caused by a disruption of plasticity as opposed to transmission. However, use of a different antagonist, ifenprodil, which selectively blocks NR2B subunitcontaining NMDA receptors, disrupts learning without affecting expression (Rodrigues et al. 2001). This suggests that NMDA receptors in the amygdala are involved in simple fear conditioning, which is consistent with the fear-potentiated startle results described above. It remains to be determined, though, whether blockade of NR2B-containing NMDA receptors in the amygdala affects the extinction of simple fear conditioning. Although preliminary findings indicate that systemic ifenprodil disrupts extinction of simple fear conditioning (Sotres-Bayon et al. 2004), this systemic effect could be caused by an effect in the mPFC or amygdala, or some other region.

Overall, results from human and animal studies strongly support the idea that the amygdala is an important site for the neural plasticity that underlies fear conditioning, and also possibly fear extinction. However, some questions remain unresolved about the neural signaling and neurophysiological response properties of amygdala neurons in extinction. More studies are needed to develop understanding about amygdala involvement during different aspects of extinction (acquisition, consolidation, retrieval); which amygdala nuclei, if any, are critically involved in each aspect; and how these interact with or depend on other structures, such as the mPFC.

\section{Role of mPFC-Amygdala Interactions in Extinction}

The presence of strong reciprocal connections between the amygdala and mPFC suggests that these regions are functionally coupled (McDonald 1991, 1998; Ghashghaei and Barbas 2002; Vertes 2004). To evaluate the possible role of interactions between the mPFC and amygdala in fear extinction, we first review their interconnections and then consider evidence for physiological interactions.

\section{Anatomical Connectivity Between the MPFC and Amygdala}

The amygdala is robustly connected with the mPFC, with different amygdala nuclei receiving projections from distinct $\mathrm{mPFC}$ regions. For example, using anterograde anatomical tracing, several studies have investigated the distribution of mPFC projections to distinct nuclei within the amygdala in rats (Sesack et al. 1989; Hurley et al. 1991; McDonald 1991; Berendse et al. 1992; McDonald et al. 1996; Vertes 2004), and in non-human primates (Room et al. 1985; Chiba et al. 2001; Ghashghaei and Barbas 2002). In general, these studies indicate that the IL sends a strong excitatory input to the LA and ITC, whereas the PL sends a similar input preferentially to the B (Berendse et al. 1992; McDonald et al. 1996). Interestingly, the B also sends projections back to the PL (Shinonaga et al. 1994; Sah et al. 2003), which in turn sends a heavy projection to the IL (Pitkänen 2001). The IL and PL also project to portions of the CE (McDonald et al. 1996), suggesting another way for $\mathrm{mPFC}$ to influence the amygdala; however, these projections are relatively sparse and thus are not focused on here.

Thus, the IL and PL are anatomically connected to the amygdala via projections to the LA, B, CE, and ITC, and are accordingly in a position to regulate amygdala function. However, the exact manner in which this regulation occurs is still being debated.

\section{Physiological Interactions Between the MPFC and Amygdala}

It has been repeatedly proposed that the reduction of conditioned fear that occurs during extinction is mediated by the connections from the mPFC to the amygdala (Morgan et al. 1993; Milad and Quirk 2002; Royer and Paré 2002; Rosenkranz et al. 2003), but the mechanisms for mPFC-induced suppression of amygdala function are not yet known.
Consistent with the anatomy, electrophysiological studies in anaesthetized rats indicate that IL stimulation evokes activity mainly in LA neurons, whereas PL stimulation evokes activity mainly in B neurons (Rosenkranz and Grace 2001, 2002). Importantly, the results reported by Rosenkranz and Grace further suggest that IL and PL stimulation directly excites inhibitory GABAergic interneurons within the LA and B, respectively, with a consequent inhibition of LA and B outputs. Indeed, Rosenkranz et al. (2003) have recently shown that mPFC stimulation can suppress LA pyramidal cell responses to a fear-arousing CS.

Given that most mPFC projections to the amygdala are excitatory (Smith et al. 2000; Rosenkranz and Grace 2001), it has been proposed that mPFC inhibition of amygdala output involves the activation of inhibitory neurons within the amygdala (Rosenkranz and Grace 2001, 2002; Quirk and Gehlert 2003; Rosenkranz et al. 2003). Two models have been proposed. One argues that $\mathrm{mPFC}$ projections stimulate inhibitory GABAcontaining interneurons in the LA and B nuclei (Grace and Rosenkranz 2002), and that these interneurons, in turn, decrease the responsiveness of excitatory LA and B projections to CE output cells (see Fig. 1A). The second model argues that mPFC projections excite inhibitory projection neurons in ITC, which, in turn, inhibit CE output neuron activity (see Fig. 1B), and thereby compete with excitatory projections from the LA and/or B to the CE (Paré 2003; Quirk et al. 2003; Paré et al. 2004). According to these competing models, extinction learning could involve mPFC activation of inhibitory interneurons within the LA/B (Grace and Rosenkranz 2002), or alternatively, mPFC activation of inhibitory projections from the ITC to the CE (Quirk et al. 2003). In each case, mPFC projections to the amygdala are considered crucial. Consistent with both models, Quirk et al. (2003) report that $\mathrm{mPFC}$ stimulation inhibits, and only inhibits, CE output neurons-that is, mPFC-induced excitation of CE output neurons was never observed. Thus far there are no published findings that discriminate between these two models.

\section{Hypothesis Test: Basal Amygdala (B) Mediates Extinction of Fear}

Three lines of evidence suggest that the B might be involved in fear extinction. The first two have already been discussed and will only be briefly mentioned.

First, many studies have explored the role of the LA and B (together as the basolateral complex) in fear extinction (Falls et al. 1992; Lee and Kim 1998; Lu et al. 2001; Marsicano et al. 2002; Walker et al. 2002; Ledgerwood et al. 2003; Lin et al. 2003a,b). Evidence from these findings strongly suggests that the B (as part of the basolateral complex) should play a role in fear extinction.

Second, the two competing physiological hypotheses described above both imply that the B is involved in fear extinction (there are other possibilities, as described below, but the most direct implication of these two hypotheses, as they are usually described, is that the B should be involved). One suggests that excitatory inputs to B inhibitory cells leads to inhibition of $\mathrm{CE}$ neurons, whereas the other suggests that excitatory inputs to B projection cells leads to excitation of inhibitory cells in the ITC, and these inhibit CE. Thus, through either of these circuits, damage to the $\mathrm{B}$ should alter fear extinction.

Third, a role for the B in fear extinction is suggested by the role of the B in contextual fear conditioning (Everitt and Robbins 1992; Kim and Fanselow 1992; Phillips and LeDoux 1992; Maren and Fanselow 1996; Anagnostaras et al. 1999) and the fact that extinction is context-dependent (Bouton and King 1983; Bouton $1988,1993,2002)$. When early studies found that damage to sensory-processing regions of the cortex led to an increased resistance to extinction (LeDoux et al. 1989; Teich et al. 1989), it 


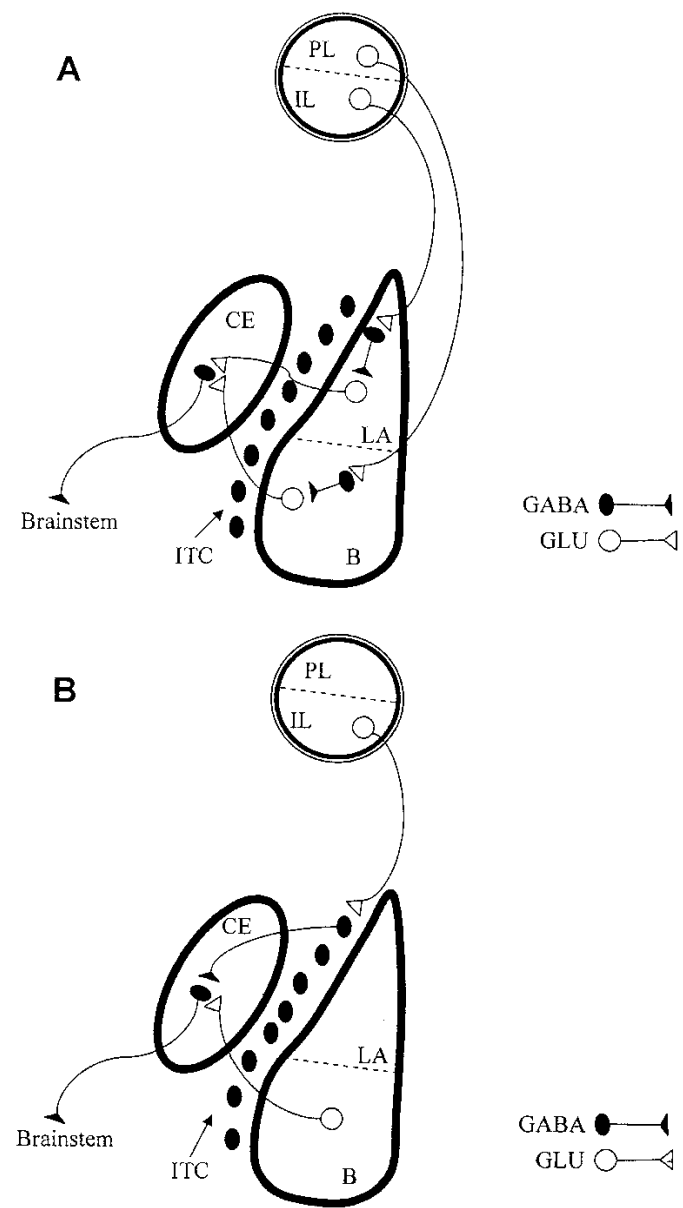

Figure 1 Two competing neural models for mPFC suppression of amygdala output. (A) Grace and Rosenkranz model: Infralimbic (IL) and prelimbic $(\mathrm{PL})$ stimulation directly excites inhibitory GABAergic interneurons within lateral (LA) and basal (B) nuclei of the amygdala, respectively, with a consequent inhibition of $\mathrm{LA}$ and $\mathrm{B}$ outputs to the central amygdala (CE), thereby influencing fear-conditioned responses via outputs to the brainstem. (B) Quirk and Paré model (modified from Quirk et al. 2003): IL projections excite inhibitory intercalated (ITC) projection neurons, which, in turn, inhibit CE output neuron activity, and thereby compete with excitatory projections to the $C E$ from the $B$, which, in turn, influence fear-conditioned responses via outputs to the brainstem. GABAergic inhibitory neurons are depicted with filled symbols; Glutamatergic (Glu) excitatory neurons are depicted with open symbols.

was proposed that sensory cortex was a necessary way-station to the $\mathrm{mPFC}$ and/or hippocampus. Although the role for the mPFC in extinction has been largely confirmed, the potential role of the hippocampus has remained relatively unexplored. Anatomical (van Groen and Wyss 1990; McDonald and Mascagni 1997; McDonald 1998; Pitkänen et al. 2000b) and electrophysiological (Colino and Fernandez de Molina 1986b; Maren and Fanselow 1995; Ishikawa and Nakamura 2003) studies indicate that there are strong reciprocal projections between the $\mathrm{B}$ and the hippocampus, as well as between the B and the mPFC (Garcia et al. 1999; Rosenkranz and Grace 1999, 2001, 2002; Pitkänen 2001; Ishikawa and Nakamura 2003). The B has been proposed as the site of contextual inputs to the amygdala in contextual conditioning (Selden et al. 1991; Everitt and Robbins 1992; Kim and Fanselow 1992; Phillips and LeDoux 1992; Maren and Fanselow 1995; Anagnostaras et al. 1999). Together these data suggest that the B may be a possible candidate for integrating information from the LA, the hippocampus, and the mPFC. Indeed, recently,
Corcoran and Maren (2001) found that the hippocampus is necessary for the context-specific expression of fear extinction, although others have reported contradictory findings (Wilson et al. 1995; Frohardt et al. 2000).

To test whether the $\mathrm{B}$ is involved in extinction, we performed bilateral electrolytic lesions of the B prior to fear conditioning, and evaluated the effects of these lesions on fear conditioning and fear extinction (Fig. 2, B lesion protocol). Consistent with other studies (Amorapanth et al. 2000; Nader et al. 2001), we found that extensive damage to the $\mathrm{B}$ (most lesions included anterior and posterior damage to the nuclei; Fig. 3) did not prevent acquisition of tone-conditioned fear (Fig. 4). Furthermore, lesions of the B did not interfere with the extinction of toneelicited fear responses (Fig. 4). This lack of effect of B lesions, which was also found in a recent experiment (Anglada-Figueroa et al. 2003), confirms that the B is not necessary for cued simple fear conditioning, but also indicates that the B is not necessary for the extinction of fear conditioning.

The dissociation of the basolateral complex into LA and B regions (each of which has further subregions) has been generally overlooked in fear extinction research. As noted above, previous studies have shown that basolateral complex manipulations alter fear extinction, which suggests that the LA and/or B are involved. Thus, our results showing that $B$ lesions have no effect on fear extinction implicate the LA, rather than the B, as the part of the basolateral complex that is involved in fear extinction, similar to its role in fear conditioning. Consistent with the idea that the LA plays a critical role in fear extinction is the finding that mPFC stimulation suppresses LA plasticity (Rosenkranz et al. 2003). Nonetheless, it is also possible that extinction additionally involves the $\mathrm{CE}$, given recent studies implicating the $\mathrm{CE}$ in fear acquisition (Paré et al. 2004; A.E. Wilensky, G.E. Schafe, M.P. Kristensen, and J.E. LeDoux, in prep.).

It should be noted that the fact that fear extinction occurs independently of the B does not necessarily discredit either of the two competing physiological hypotheses about fear extinction described above. That is, the mPFC could suppress amygdalamediated fear via direct projections to the LA or ITC, rather than to the B. We return to this point below.

An important issue that is emphasized by our finding is that researchers interested in extinction or other functions mediated by the amygdala should, when possible, use the known detailed

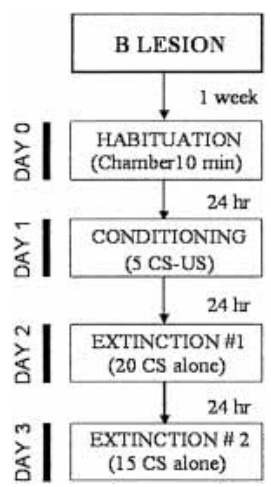

Figure 2 Basal amygdala lesion protocol. Rats were subjected to bilateral electrolytic lesion of the basal amygdala, and left to recover for 1 wk. Fear conditioning occurred in Context A, and extinction training took place in Context B. On Day 0 , rats were habituated to each context for 10 min, with a 2-h interval between each context habituation. On Day 1, rats were fear-conditioned with five tone-footshock (CS-US) pairings. Extinction sessions were conducted on the following $2 \mathrm{~d}$. On Day 2, rats were exposed to 20 CS alone presentations in Context B. Finally on Day 3, rats were exposed to 15 trials of CS alone presentations in Context B. 


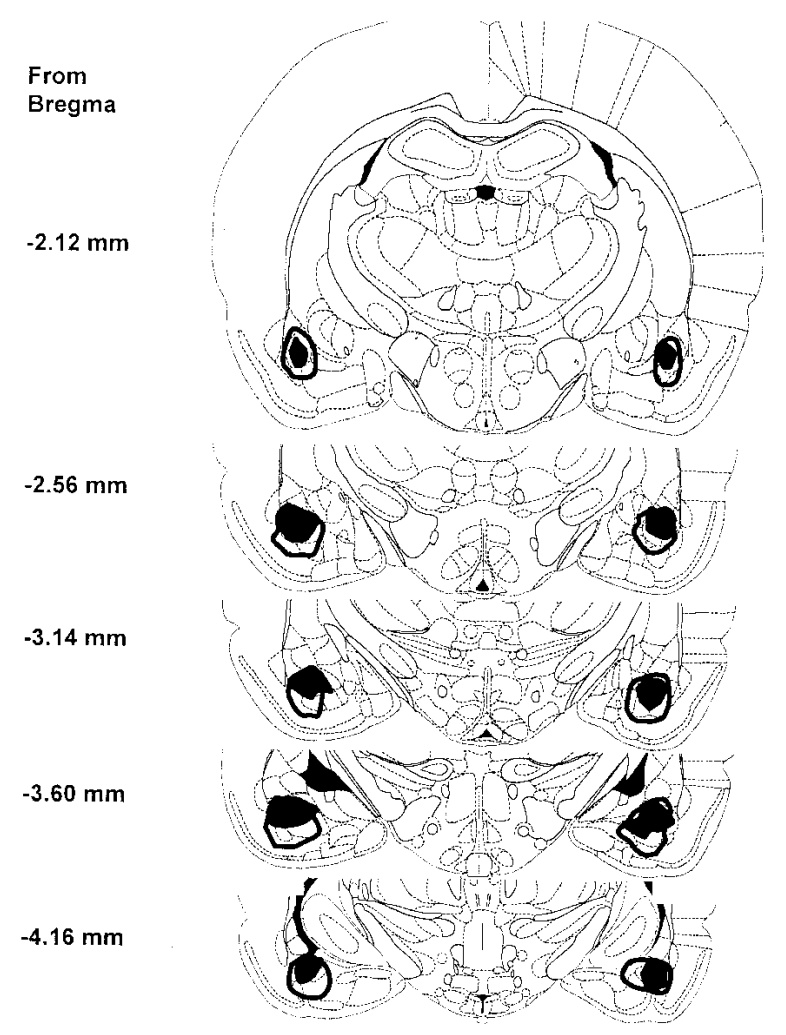

Figure 3 Representation of the maximal (outlined region) and minimal (filled region) basal amygdala lesions. The numbers in bold indicate the distance posterior to bregma.

anatomical partitioning of the amygdala into nuclei and subnuclei (Amaral et al. 1992; Pitkänen et al. 1997, Pitkänen 2001), rather than rely on less precise concepts, such as the basolateral complex.

\section{Assessment of the Contribution of mPFC and Amygdala Interactions}

\section{Implications for Models of mPFC-Amygdala Interactions}

The importance of $\mathrm{mPFC}$ regulation over amygdala function for the extinction of conditioned fear is strongly supported by research that has progressed throughout the past decade. The original findings of Morgan et al. (1993) showed that ventral mPFC lesions disrupt fear extinction, and recent results indicate a specific role for the MPFC, particularly the IL, in the retrieval and possibly the storage of prior extinction learning (Quirk et al. 2000; Garcia 2002; Morgan et al. 2003). Thus, we now have a strong basis for the initial proposal that disruption of mPFC control over amygdala function can result in emotional perseveration (Morgan et al. 1993; Morgan and LeDoux 1995).

Nonetheless, much work remains to be done. We still do not know the crucial neurophysiological mechanisms that underlie mPFC control over amygdala-mediated fear responses. Our current evaluation of the role for the $\mathrm{B}$, by performing selective $\mathrm{B}$ lesions that spared the LA, indicates that the $\mathrm{B}$ is not a crucial locus for extinction. The possibility remains that $\mathrm{mPFC}$ projections to inhibitory neurons within the LA are critically involved (Rosenkranz and Grace 2001, 2002; Grace and Rosenkranz 2002), or alternatively that $\mathrm{mPFC}$ projections to the ITC regulate LA inputs to the CE (Quirk et al. 2003). Indeed, as discussed above, Rosenkranz et al. (2003) have shown that mPFC stimulation can suppress LA plasticity during conditioning, and can also suppress LA responses to cues that have been previously fear-conditioned. These results emphasize the possibility that mPFC-mediated alterations of plasticity within the LA may be important for extinction learning, and also that mPFC inputs to inhibitory cells within the LA may be activated during the retrieval of prior extinction learning.

\section{Model for Hippocampal-Based Contextual Constraints on Extinction}

It has long been recognized that extinction depends on the learning of a new inhibitory (i.e., a CS-NoUS) association that competes with the original excitatory (i.e., CS-US) association (Bouton 2002; Davis and Myers 2002; Myers and Davis 2002). After extinction, the original conditioned response can be "renewed" if the CS is presented in a context that is distinct from the one in which extinction learning occurred (Bouton 2002). This renewal not only demonstrates that the original excitatory association remains intact, but also suggests that the extinction of cued fear is largely dependent on the context. In essence, the retrieval of extinction learning appears to be contextually constrained.

Corcoran and Maren (2001) have shown that reversible inactivation of the dorsal hippocampus with muscimol disrupts the context-specific expression of prior extinction learning. Specifically, intrahippocampal muscimol infusions appeared to remove contextual constraints on the retrieval or expression of extinction to a tone CS, thereby abolishing the capacity of a context change to renew the original conditioned fear response. Intrahippocampal muscimol had no effect on tone-elicited fear when rats had not been previously extinguished (Corcoran and Maren 2001), indicating that the reduced freezing was not attributable to a general reduction of fear.

The possibility that hippocampal afferents to the B might be important for contextual contributions to cued fear extinction was one factor that motivated the current experiment (see Fig. $5 \mathrm{~A})$. However, our results suggest that convergence of mPFC and hippocampal inputs within the B is not important for the learning or expression of extinction. Thus, an alternative model is needed, one that incorporates the current result with the evidence for both mPFC (Quirk et al. 2000; Grace and Rosenkranz 2002; Barrett et al. 2003) and hippocampal (Corcoran and Maren 2001; Barrett et al. 2003) contributions to extinction of cued fear (see Fig. 5B).

Strong hippocampal projections from the CA1/subiculum to the mPFC have been identified (Jay and Witter 1991; Conde et al.

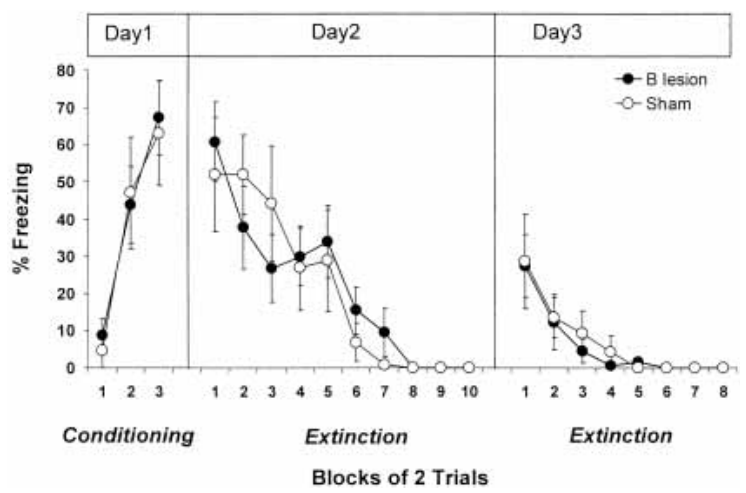

Figure 4 Basal amygdala lesions do not interfere with the extinction of tone-elicited fear. Percent freezing to the tone is shown in blocks of two trials (except for first trial of conditioning and last trial of extinction in Day 3). Basal lesion (filled circles; $n=7$ ) and Sham (open circles; $n=8$ ). Freezing was assessed initially using an automated system (see Materials and Methods section), and then confirmed by observing the rat's behavior stored on videotape. 
Prefrontal-Amygdala Interactions in Fear Extinction

A

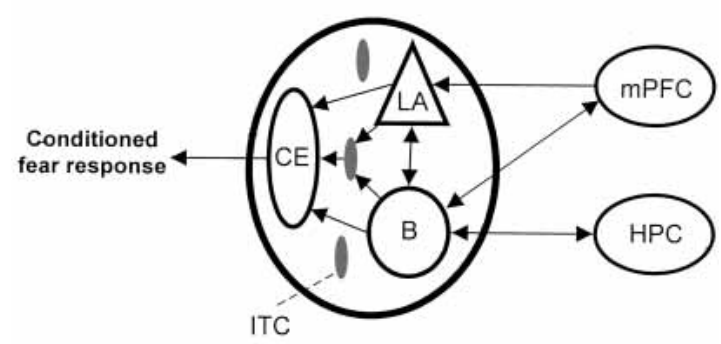

B

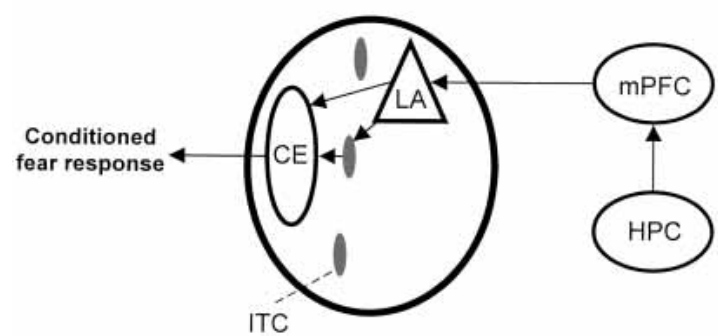

Figure 5 Model for contextual modulation of fear extinction. $(A)$ Model A emphasizes the convergence of projections from the medial prefrontal cortex (mPFC) and hippocampus (HPC) to the basal amygdala (B). However, our results show that the $B$ is not necessary for fear extinction, and we therefore propose an alternative model. $(B)$ This model excludes the $B$ and emphasizes the importance of HPC modulation of mPFC control over lateral amygdala (LA) projections to the central amygdala (CE). For clarity, we omitted two other connections that could be involved: mPFC connection to ITC cells, and a weak projection from the HPC proper directly to the LA.

1995), and form mainly excitatory synapses (Carr and Sesack 1996). Recent electrophysiological findings indicate that stimulation of hippocampal cells induces monosynaptic, AMPAreceptor-dependent activation of $\mathrm{mPFC}$ neurons, localized primarily within the IL and ventral PL regions (Degenetais et al. 2003; Ishikawa and Nakamura 2003). Moreover, these sites correspond with mPFC stimulation sites that evoke activity of LA cells (Rosenkranz and Grace 1999, 2001, 2002; Ishikawa and Nakamura 2003), and perhaps the ITC as well (Quirk et al. 2003). Overall, these anatomical/electrophysiological findings, together with the behavioral findings (Quirk et al. 2000; Corcoran and Maren 2001; Barrett et al. 2003; Rosenkranz et al. 2003), suggest that hippocampal inputs to mPFC cells may subserve contextual constraints on the retrieval of cued fear extinction.

Furthermore, Hobin et al. (2003) found that after extinction training, CS-elicited firing in LA neurons was suppressed only in the extinction context. This finding led them to propose a model whereby context-specific hippocampal-mPFC interactions modulate conditioned fear responses by inhibiting projections from the LA to the B to the CE. However, because electrolytic $B$ lesions have no effect on the expression or extinction of conditioned fear, we propose that Figure 5B more accurately depicts the circuitry underlying contextual constraints on extinction.

\section{Role of the LA in Extinction Learning}

As noted above, intra-amygdala infusions of an NMDA antagonist or MAPK inhibitor disrupted extinction learning (Falls et al. 1992; Lu et al. 2001), and similar infusions of an NMDA agonist enhanced extinction learning (Walker et al. 2002; Ledgerwood et al. 2003). More recently, endocannabinoids in the amygdala have been implicated, because cannabinoid receptor 1 receptor knockout mice show disrupted extinction of fear, and endocannabinoids are elevated in the LA and B during extinction training (Marsicano et al. 2002). Finally, gastrin-releasing peptide (Grp) is highly expressed in the LA, and receptors for this peptide are localized on LA GABAergic interneurons. Mice lacking these Grp receptors showed decreased inhibition of LA pyramidal neurons, greater conditioned fear, and resistance to extinction, suggesting that Grp may endogenously regulate LA outputs to the CE by stimulating inhibitory interneurons (Shumyatsky et al. 2002). Collectively, these findings suggest that molecular events within the amygdala may be crucially activated during extinction learning, and because we have shown that the B is not needed for the extinction of simple cued fear conditioning, we emphasize that the LA is the probable candidate for the extinction-related functional consequences of these molecular signals.

Considerable data have been amassed throughout the past decade to suggest that both the MPFC and the LA are part of a circuit whereby the amygdala-processed underlying conditioned fear responses are suppressed by descending $\mathrm{mPFC}$ control. Moreover, this mPFC control over the LA is specifically needed for the retrieval of prior extinction learning, rather than for the acquisition of fear extinction per se, and this mPFC-mediated retrieval of extinction appears to be contextually constrained. Accordingly, consistent with Hobin et al. (2003), we emphasize that hippocampal inputs to the mPFC may set the circumstances for mPFC-mediated control over amygdala fear circuitry. However, the B does not appear to be crucially involved. Since molecular events within the LA itself are implicated in fear learning (e.g. LeDoux 2000; Blair et al. 2001; Maren 2001; Schafe et al. 2001) extinction learning may require additional events within the LA that suppress the fear memory. Thus, synaptic plasticity within the LA may be crucial for establishing specific mFPC-LA connections that are activated later, at the time of extinction retrieval.

\section{Clinical Implications of mPFC-Amygdala Interactions}

We have emphasized the role of animal studies in suggesting the importance of interactions between the $\mathrm{MPFC}$ and amygdala in fear regulation. However, studies in humans also implicate interactions between these two brain structures in several affective disorders.

In fear extinction, the appropriate regulatory interaction between the mPFC and the amygdala is critical for the organism to adapt as situations change. Failure in this naturally occurring mechanism can lead to inadequate and maladaptive affectrelated behaviors, referred to as emotional preservation. Similar emotional preservation occurs in several mental disorders, and may well involve the dysfunction of the mPFC-amygdala interaction. In fact, it has been argued that when the mPFC-amygdala interaction is compromised, certain types of mental disorders can develop, such as depression (Drevets 1998, 1999, 2001, 2003; Davidson 2002b; Siegle et al. 2003), anxiety (Davidson 2002a), and fear disorders, including posttraumatic stress disorder (Quirk and Gehlert 2003; Rothbaum and Davis 2003). For instance, functional neuroimaging studies have identified that the amygdala is hyperactive (Siegle et al. 2002) and the mPFC is hypoactive (Drevets et al. 1992, 1998; Drevets 2003) in depressed patients. Furthermore, several studies with humans have shown that functional activity in the mPFC is inversely related to amygdala activity (Abercrombie et al. 1998; Davidson et al. 1999, 2000; Davidson 2002a,b; Anand and Shekhar 2003), and posttraumatic stress disorder patients show an unusually high activation in the amygdala and lower than normal activity in the mPFC when exposed to threatening stimuli (Bremner et al. 1999; Fernandez et al. 2001; Shin et al. 2001). 


\section{Conclusions}

Animal models suggest that under normal circumstances the mPFC and amygdala orchestrate the control of affective states by regulating each other at particular moments in an emotional experience. Clinical evidence suggests these interactions may be compromised in certain emotional disorders. Advances that are made using animal models of fear extinction are crucial to developing our knowledge, which it is hoped will lead to treatments for these disorders.

\section{MATERIALS AND METHODS}

Subjects were adult male Sprague-Dawley rats housed individually in Plexiglas cages. Rats weighed between 325 and $350 \mathrm{~g}$ upon arrival at the laboratory and were kept on a 12-12-h light-dark cycle (lights on at 0700). Rats had ad libitum access to food and water throughout the duration of the experiment.

Bilateral electrolytic lesion of the B was made according to previously published procedures (Amorapanth et al. 2000; Nader et al. 2001). For surgery, rats were anaesthetized with pentobarbital $(50 \mathrm{mg} / \mathrm{kg}$, i.p.) and placed into the stereotaxic frame. The skull was exposed and four holes per side were drilled over the B using a dental drill. Electrolytic lesions were made by passing positive current $(0.5 \mathrm{~mA})$ at each site through a monopolar electrode insulated with epoxy to within $200 \mu \mathrm{m}$ of the tip. Coordinates (in millimeters relative to the skull surface at bregma) were: anterior/posterior $=2.1,2.8,3.3$, and $4.2 ;$ medial $/$ lateral $=4.9$, 4.9, 5.3, and 5.3; and dorsal/ventral = 9.1, 9.3, 9.2, and 9.3 (Paxinos and Watson 1998). Respectively, current durations (in seconds) were $12,15,15$, and 15 . Only rats with lesions localized to the B sparing other amygdala regions were included in the analysis ( $n=7$; see Fig. 3$)$, and 12 rats were excluded, either because there was insufficient damage to the B bilaterally or there was damage to other amygdala nuclei. Sham rats $(n=8)$ received the same treatment except that electrodes were placed 1-2 $\mathrm{mm}$ above the B and current was not passed through the electrode. After surgery, rats were allowed to recover in their home cages for $1 \mathrm{wk}$. A third group (naive: $n=8$; data not shown) did not receive any surgery, but was subjected to the same behavioral procedures.

Behavioral procedures took place in two different contexts (Context A and Context B) to avoid possible confound influences of the hippocampal-dependent context conditioning. Chambers were contained within a sound isolation cubicle (Model H10$24 \mathrm{~A}$; Coulbourn Instruments), and equipped with an overhead infrared motion detector that continuously monitored all movement in the chamber. Recorded activity was acquired at a temporal resolution of $20 \mathrm{msec}$ through a computer running Graphics Notation software (Coulbourn Instruments) that also controlled stimulus presentation. Behavior was also monitored with an infrared camera and recorded on videotape for visual confirmation of the automated recording. Context A consisted of a conditioning chamber with a steel rod floor. A single house light illuminated the chamber. Context B was a modification of Context $A$ in which the metal grid floor was covered with a sheet of transparent plastic previously wiped with peppermint-scented soap and the house light was off. Fear conditioning occurred in Context A, and extinction training took place in Context B. For all rats, CS-US or CS-noUS trials were preceded by a 4-min period in which they were allowed to explore the chamber. On Day 0 , rats were habituated to each context for $10 \mathrm{~min}$, with a 2-h interval between each context habituation. On Day 1, fear conditioning occurred. The rats were allowed to explore for $4 \mathrm{~min}$ and then received five tone-footshock pairings (CS-US; CS tone $=20$ sec, $80 \mathrm{~dB}, 10 \mathrm{kHz}$; US footshock $=1 \mathrm{sec}, 0.6 \mathrm{~mA}$; intertrial interval $=$ average 2 min [range $1-3 \mathrm{~min}]$ ). The next day, Day 2 , rats were exposed to their first extinction session in Context B. The rats were allowed to explore for $4 \mathrm{~min}$ before they were exposed to 20 tone-alone (CS-noUS) presentations. Finally on Day 3, rats were exposed to 15 trials of tone-alone presentations (CS-noUS) in Context B.

Following completion of the behavioral testing, rats were given an overdose of chloral hydrate $(25 \%, 1 \mathrm{cc} / 100 \mathrm{~g})$ and per- fused with physiological saline followed by $10 \%$ buffered formalin. The brains were stored in a 30\% sucrose, 10\% formalin solution for at least $4 \mathrm{~d}$. Brains were then frozen and cut into $40-\mu \mathrm{m}$ sections using a cryostat, with every other section through the lesion site mounted on a subbed slide and stained with cresyl violet. Sections were examined and images were digitally captured under light microscope.

Freezing was used as the measure of conditioned emotional response. Freezing was defined as immobility with the exception of respiratory-related movement and non-awake or rest body posture (i.e., curled up). Freezing was assessed initially using an automated system, and then confirmed by observing the rat's behavior stored on videotape.

\section{ACKNOWLEDGMENTS}

This work was supported by R01 MH46516, R37 MH38774, P50 MH58911, and K05 MH067048 to J.E.L.

\section{REFERENCES}

Abercrombie, H.C., Schaefer, S.M., Larson, C.L., Oakes, T.R., Lindgren, K.A., Holden, J.E., Perlman, S.B., Turski, P.A., Krahn, D.D., Benca, R.M., et al. 1998. Metabolic rate in the right amygdala predicts negative affect in depressed patients. Neuroreport 9: 3301-3307.

Amaral, D.G., Price, J.L., Pitkänen, A., and Carmichael, S.T. 1992. Anatomical organization of the primate amygdaloid complex. In The amygdala: Neurobiological aspects of emotion, memory, and mental dysfunction (ed. J.P. Aggleton), pp. 1-66. Wiley-Liss, Inc. New York.

Amorapanth, P., LeDoux, J.E., and Nader, K. 2000. Different lateral amygdala outputs mediate reactions and actions elicited by a fear-arousing stimulus. Nat. Neurosci. 3: 74-79.

Anagnostaras, S.G., Maren, S., and Fanselow, M.S. 1999. Temporally graded retrograde amnesia of contextual fear after hippocampal damage in rats: Within-subjects examination. J. Neurosci. 19: 1106-1114.

Anand, A. and Shekhar, A. 2003. Brain imaging studies in mood and anxiety disorders: Special emphasis on the amygdala. Ann. NY Acad. Sci. 985: 370-388.

Anglada-Figueroa, D., Milad, M.R., and Quirk, G.J. 2003. Basal amygdala lesions impair within-session extinction of conditioned fear. Soc. Neurosci. Abstr. 199.6.

Atkins, C.M., Selcher, J.C., Petraitis, J.J., Trzaskos, J.M., and Sweatt, J.D. 1998. The MAPK cascade is required for mammalian associative learning. Nat. Neurosci. 1: 602-609.

Barrett, D., Shumake, J., Jones, D., and Gonzalez-Lima, F. 2003. Metabolic mapping of mouse brain activity after extinction of a conditioned emotional response. J. Neurosci. 23: 5740-5749.

Bechara, A., Damasio, H., Tranel, D., and Anderson, S.W. 1998. Dissociation of working memory from decision making within the human prefrontal cortex. J. Neurosci. 18: 428-437.

Bechara, A., Damasio, H., and Damasio, A.R. 2000. Emotion, decision making and the orbitofrontal cortex. Cereb. Cortex 10: 295-307.

Berendse, H.W., Galis de Graaf, Y., and Groenewegen, H.J. 1992. Topographical organization and relationship with ventral striatal compartments of prefrontal corticostriatal projections in the rat. $J$. Comp. Neurol. 316: 314-347.

Berman, D.E. and Dudai, Y. 2001. Memory extinction, learning anew, and learning the new: Dissociations in the molecular machinery of learning in cortex. Science 291: 2417-2419.

Berns, G.S., McClure, S.M., Pagnoni, G., and Montague, P.R. 2001. Predictability modulates human brain response to reward. $J$. Neurosci. 21: 2793-2798.

Blair, H.T., Schafe, G.E., Bauer, E.P., Rodrigues, S.M., and LeDoux, J.E. 2001. Synaptic plasticity in the lateral amygdala: A cellular hypothesis of fear conditioning. Learn. Mem. 8: 229-242.

Blair, H.T., Tinkelman, A., Moita, M.A., and LeDoux, J.E. 2003. Associative plasticity in neurons of the lateral amygdala during auditory fear conditioning. Ann. NY Acad. Sci. 985: 485-487.

Bliss, T.V. and Collingridge, G.L. 1993. A synaptic model of memory: Long-term potentiation in the hippocampus. Nature 361: 31-39.

Botvinick, M., Nystrom, L.E., Fissell, K., Carter, C.S., and Cohen, J.D. 1999. Conflict monitoring versus selection-for-action in anterior cingulate cortex. Nature 402: 179-181.

Bouton, M.E. 1988. Context and ambiguity in the extinction of emotional learning: Implications for exposure therapy. Behav. Res. Ther. 26: 137-149.

. 1993. Context, time, and memory retrieval in the interference paradigms of Pavlovian learning. Psychol. Bull. 114: 80-99.

- 2002. Context, ambiguity, and unlearning: Sources of relapse after behavioral extinction. Biol. Psychiatry 52: 976-986.

Bouton, M.E. and King, D.A. 1983. Contextual control of the extinction 
of conditioned fear: Tests for the associative value of the context. $J$ Exp. Psychol. Anim. Behav. Process 9: 248-265.

Bremner, J.D., Staib, L.H., Kaloupek, D., Southwick, S.M., Soufer, R., and Charney, D.S. 1999. Neural correlates of exposure to traumatic pictures and sound in Vietnam combat veterans with and without posttraumatic stress disorder: A Positron Emission Tomography study. Biol. Psychiatry 45: 806-816.

Bush, G., Luu, P., and Posner, M. 2000. Cognitive and emotional influences in anterior cingulate cortex. Trends Cogn. Sci. 4: 215-222.

Carr, D.B. and Sesack, S.R. 1996. Hippocampal afferents to the rat prefrontal cortex: Synaptic targets and relation to dopamine terminals. J. Comp. Neurol. 369: 1-15.

Carter, C.S., Botvinick, M.M., and Cohen, J.D. 1999. The contribution of the anterior cingulate cortex to executive processes in cognition. Rev. Neurosci. 10: 49-57.

Chiba, T., Kayahara, T., and Nakano, K. 2001. Efferent projections of infralimbic and prelimbic areas of the medial prefrontal cortex in the Japanese monkey, Macaca fuscata. Brain Res. 888: 83-101.

Cohen, J.D., Botvinick, M., and Carter, C.S. 2000. Anterior cingulate and prefrontal cortex: Who's in control? Nat. Neurosci. 3: 421-423.

Colino, A. and Fernandez de Molina, A. 1986a. Electrical activity generated in subicular and entorhinal cortices after electrical stimulation of the lateral and basolateral amygdala of the rat. Neuroscience 19: 573-580.

. 1986b. Inhibitory response in entorhinal and subicular cortices after electrical stimulation of the lateral and basolateral amygdala of the rat. Brain Res. 378: 416-419.

Collins, D.R. and Paré, D. 1999. Reciprocal changes in the firing probability of lateral and central medial amygdala neurons. $J$. Neurosci. 19: 836-844.

- 2000. Differential fear conditioning induces reciprocal changes in the sensory responses of lateral amygdala neurons to the $\mathrm{CS}^{+}$and $\mathrm{CS}^{-}$. Learn. Mem. 7: 97-103.

Conde, F., Maire Lepoivre, E., Audinat, E., and Crepel, F. 1995. Afferent connections of the medial frontal cortex of the rat. II. Cortical and subcortical afferents. J. Comp. Neurol. 352: 567-593.

Corcoran, K.A. and Maren, S. 2001. Hippocampal inactivation disrupts contextual retrieval of fear memory after extinction. J. Neurosci. 21: $1720-1726$.

Curtis, C.E. and D'Esposito, M. 2003. Success and failure suppressing reflexive behavior. J. Cogn. Neurosc. 15: 409-418.

Damasio, A.R. 1990. Synchronous activation in multiple cortical regions: A mechanism for recall. Semin. Neurosci. 2: 287-296.

Davidson, R.J. 2002a. Anxiety and affective style: Role of prefrontal cortex and amygdala. Biol. Psychiatry 51: 68-80.

. 2002b. Depression: Perspectives from affective neuroscience. Annu. Rev. Psychol. 53: 545-574.

Davidson, R.J., Abercrombie, H., Nitschke, J.B., and Putnam, K. 1999. Regional brain function, emotion and disorders of emotion. Curr. Opin. Neurobiol. 9: 228-234.

Davidson, R.J., Putnam, K.M., and Larson, C.L. 2000. Dysfunction in the neural circuitry of emotion regulation-A possible prelude to violence. Science 289: 591-594.

Davis, M. 2002. Role of NMDA receptors and MAP kinase in the amygdala in extinction of fear: Clinical implications for exposure therapy. Eur. J. Neurosci. 16: 395-398.

Davis, M. and Myers, K.M. 2002. The role of glutamate and $\gamma$-aminobutyric acid in fear extinction: Clinical implications for exposure therapy. Biol. Psychiatry 52: 998-1007.

Davis, M. and Whalen, P.J. 2001. The amygdala: Vigilance and emotion. Mol. Psychiatry 6: 13-34.

Davis, M., Walker, D.L., and Myers, K.M. 2003. Role of the amygdala in fear extinction measured with potentiated startle. Ann. NY Acad. Sci. 985: 218-232.

Degenetais, E., Thierry, A.M., Glowinski, J., and Gioanni, Y. 2003. Synaptic influence of hippocampus on pyramidal cells of the rat prefrontal cortex: An in vivo intracellular recording study. Cerebral Cortex 13: 782-792.

D'Esposito, M., Postle, B.R., and Rypma, B. 2000. Prefrontal cortical contributions to working memory: Evidence from event-related fMRI studies. Exp. Brain Res. 133: 3-11.

Drevets, W.C. 1998. Functional neuroimaging studies of depression: The anatomy of melancholia. Ann. Rev. Med. 49: 341-361.

. 1999. Prefrontal cortical-amygdalar metabolism in major depression. Ann. NY Acad. Sci. 877: 614-637.

. 2001. Neuroimaging and neuropathological studies of depression: Implications for the cognitive-emotional features of mood disorders. Curr. Opin. Neurobiol. 11: 240-249.

- 2003. Neuroimaging abnormalities in the amygdala in mood disorders. Ann. NY Acad. Sci. 985: 420-444.

Drevets, W.C., Videen, T.O., Price, J.L., Preskorn, S.H., Carmichael, S.T. and Raichle, M.E. 1992. A functional anatomical study of unipolar depression. J. Neurosci. 12: 3628-3641.

Drevets, W.C., Ongur, D., and Price, J.L. 1998. Neuroimaging abnormalities in the subgenual prefrontal cortex: Implications for the pathophysiology of familial mood disorders. Mol. Psychiatry 3: $220-226$.

Everitt, B.J. and Robbins, T.W. 1992. Amygdala-ventral striatal interactions and reward related processes. In The amygdala: Neurobiological aspects of emotion, memory and mental dysfunction (ed. J.P. Aggleton), pp. 400-429. Wiley-Liss, Inc., New York.

Falls, W.A., Miserendino, M.J., and Davis, M. 1992. Extinction of fear-potentiated startle: Blockade by infusion of an NMDA antagonist into the amygdala. J. Neurosci. 12: 854-863.

Fanselow, M.S. 1998. Pavlovian conditioning, negative feedback, and blocking: Mechanisms that regulate association formation. Neuron 20: $625-627$.

Fernandez, M., Pissiota, A., Frans, O., von Knorring, L., Fischer, H., and Fredrikson, M. 2001. Brain function in a patient with torture related post-traumatic stress disorder before and after fluoxetine treatment: A Positron Emission Tomography provocation study. Neurosci. Lett. 297: $101-104$.

Frohardt, R.J., Guarraci, F.A., and Bouton, M.E. 2000. The effects of neurotoxic hippocampal lesions on two effects of context after fear extinction. Behav. Neurosci. 114: 227-240.

Garcia, R. 2002. Postextinction of conditioned fear: Between two CS-related memories. Learn. Mem. 9: 361-363.

Garcia, R., Vouimba, R.M., Baudry, M., and Thompson, R.F. 1999. The amygdala modulates prefrontal cortex activity relative to conditioned fear. Nature 402: 294-296.

Gewirtz, J.C., Falls, W.A., and Davis, M. 1997. Normal conditioned inhibition and extinction of freezing and fear-potentiated startle following electrolytic lesions of medical prefrontal cortex in rats. Behav. Neurosci. 111: 712-726.

Ghashghaei, H.T. and Barbas, H. 2002. Pathways for emotion: Interactions of prefrontal and anterior temporal pathways in the amygdala of the rhesus monkey. Neuroscience 115: 1261-1279.

Goldman-Rakic, P.S. 1987. Circuitry of primate prefrontal cortex and regulation of behavior by representational memory. In Handbook of physiology: The nervous system (ed. F. Plum), pp. 373-418. American Physiology Society, Bethesda, MD.

. 1995. Architecture of the prefrontal cortex and the central executive. Ann. NY Acad. Sci. 769: 71-83.

Goosens, K.A. and Maren, S. 2001. Contextual and auditory fear conditioning are mediated by the lateral, basal, and central amygdaloid nuclei in rats. Learn. Mem. 8: 148-155.

Goosens, K.A., Hobin, J.A., and Maren, S. 2003. Auditory-evoked spike firing in the lateral amygdala and Pavlovian fear conditioning: Mnemonic code or fear bias? Neuron 40: 1013-1022.

Grace, A.A. and Rosenkranz, J.A. 2002. Regulation of conditioned responses of basolateral amygdala neurons. Physiol. Behav. 77: 489-493.

Heidbreder, C.A. and Groenewegen, H.J. 2003. The medial prefrontal cortex in the rat: Evidence for a dorso-ventral distinction based upon functional and anatomical characteristics. Neurosci. Biobehav. Rev. 27: 555-579.

Herry, C. and Garcia, R. 2002. Prefrontal cortex long-term potentiation, but not long-term depression, is associated with the maintenance of extinction of learned fear in mice. J. Neurosci. 22: 577-583.

. 2003. Behavioral and paired-pulse facilitation analyses of long-lasting depression at excitatory synapses in the medial prefrontal cortex in mice. Behav. Brain Res. 146: 89-96.

Herry, C., Vouimba, R.M., and Garcia, R. 1999. Plasticity in the mediodorsal thalamo-prefrontal cortical transmission in behaving mice. J. Neurophys. 82: 2827-2832.

Hobin, J.A., Goosens, K.A., and Maren, S. 2003. Context-dependent neuronal activity in the lateral amygdala represents fear memories after extinction. J. Neurosci. 23: 8410-8416.

Hugdahl, K., Berardi, A., Thompson, W.L., Kosslyn, S.M., Macy, R., Baker, D.P., Alpert, N.M., and LeDoux, J.E. 1995. Brain mechanisms in human classical conditioning: A PET blood flow study. Neuroreport 6: $1723-1728$

Hurley, K.M., Herbert, H., Moga, M.M., and Saper, C.B. 1991. Efferent projections of the infralimbic cortex of the rat. J. Comp. Neurol. 308: $249-276$.

Ishikawa, A. and Nakamura, S. 2003. Convergence and interaction of hippocampal and amygdalar projections within the prefrontal cortex in the rat. J. Neurosci. 23: 9987-9995.

Jay, T.M. and Witter, M.P. 1991. Distribution of hippocampal CA1 and subicular efferents in the prefrontal cortex of the rat studied by means of anterograde transport of Phaseolus vulgaris-leucoagglutinin. J. Comp. Neurol. 313: 574-586.

Kim, J.J. and Fanselow, M.S. 1992. Modality-specific retrograde amnesia of fear. Science 256: 675-677.

Krettek, J.E. and Price, J.L. 1978. A description of the amygdaloid 
complex in the rat and cat with observations on intra-amygdaloid axonal connections. J. Comp. Neurol. 178: 255-280.

Lebron, K., Milad, M.R., and Quirk, G.J. 2003. Rats with lesions of the ventromedial prefrontal cortex can eventually recall extinction, with additional training. Soc. Neurosci. Abstr. 199.5.

Ledgerwood, L., Richardson, R., and Cranney, J. 2003. Effects of D-cycloserine on extinction of conditioned freezing. Behav. Neurosci. 117: $341-349$.

LeDoux, J.E. 1996. The emotional brain: The mysterious underpinnings of emotional life, p. 384. Simon \& Schuster, New York.

. 2000. Emotion circuits in the brain. Annu. Rev. Neurosci. 23: $155-184$.

LeDoux, J.E. and Gorman, J.M. 2001. A call to action: Overcoming anxiety through active coping. Am. J. Psychiatry 158: 1953-1955.

LeDoux, J.E., Romanski, L.M., and Xagoraris, A. 1989. Indelibility of subcortical emotional memories. J. Cogn. Neurosci. 8: 2517-2529.

Lee, H. and Kim, J.J. 1998. Amygdalar NMDA receptors are critical for new fear learning in previously fear-conditioned rats. J. Neurosci. 18: $8444-8454$.

Levy, R. and Goldman-Rakic, P.S. 2000. Segregation of working memory functions within the dorsolateral prefrontal cortex. Exp. Brain Res. 133: $23-32$.

Li, X.F., Phillips, R., and LeDoux, J.E. 1995. NMDA and non-NMDA receptors contribute to synaptic transmission between the medial geniculate body and the lateral nucleus of the amygdala. Exp. Brain. Res. 105: 87-100.

Li, X.F., Stutzmann, G.E., and LeDoux, J.E. 1996. Convergent but temporally separated inputs to lateral amygdala neurons from the auditory thalamus and auditory cortex use different postsynaptic receptors: In vivo intracellular and extracellular recordings in fear conditioning pathways. Learn. Mem. 3: 229-242.

Li, R., Nishijo, H., Ono, T., Ohtani, Y., and Ohtani, O. 2002. Synapses on GABAergic neurons in the basolateral nucleus of the rat amygdala: Double-labeling immunoelectron microscopy. Synapse 43: $42-50$.

Lin, C.H., Lee, C.C., and Gean, P.W. 2003a. Involvement of a calcineurin cascade in amygdala depotentiation and quenching of fear memory. Mol. Pharmacol. 63: 44-52.

Lin, C.H., Yeh, S.H., Lu, H.Y., and Gean, P.W. 2003b. The similarities and diversities of signal pathways leading to consolidation of conditioning and consolidation of extinction of fear memory. $J$. Neurosci. 23: 8310-8317.

Lu, K.T., Walker, D.L., and Davis, M. 2001. Mitogen-activated protein kinase cascade in the basolateral nucleus of amygdala is involved in extinction of fear-potentiated startle. J. Neurosci. 21: RC162.

Luria, A.R. 1973a. The frontal lobes and the regulation of behavior. In Psychophysiology of the frontal lobes (ed. A.R. Luria), pp. 3-26. Academic Press. New York.

. 1973b. The working brain. Basic Books, New York.

Maren, S. 2001. Neurobiology of Pavlovian fear conditioning. Annu. Rev. Neurosci. 24: 897-931.

Maren, S. and Fanselow, M.S. 1995. Synaptic plasticity in the basolateral amygdala induced by hippocampal formation stimulation in vivo. J. Neurosci. 15: 7548-7564.

. 1996. The amygdala and fear conditioning: Has the nut been cracked? Neuron 16: 237-240.

Maren, S., Aharonov, G., Stote, D.L., and Fanselow, M.S. 1996. $\mathrm{N}$-Methyl-D-aspartate receptors in the basolateral amygdala are required for both acquisition and expression of conditional fear in rats. Behav. Neurosci. 110: $1365-1374$.

Marsicano, G., Wotjak, C.T., Azad, S.C., Bisogno, T., Rammes, G. Cascio, M.G., Hermann, H., Tang, J., Hofmann, C., Zieglgansberger, W., et al. 2002. The endogenous cannabinoid system controls extinction of aversive memories. Nature 418: 530-534.

Martin, S.J., Grimwood, P.D., and Morris, R.G. 2000. Synaptic plasticity and memory: An evaluation of the hypothesis. Ann. Rev. Neurosci. 23: $649-711$

McDonald, A.J. 1985. Immunohistochemical identification of $\gamma$-aminobutyric acid-containing neurons in the rat basolateral amygdala. Neurosci. Lett. 53: 203-207.

- 1991. Organization of amygdaloid projections to the prefrontal cortex and associated striatum in the rat. Neuroscience 44: 1-14. . 1998. Cortical pathways to the mammalian amygdala. Prog. Neurobiol. 55: 257-332.

McDonald, A.J. and Augustine, J.R. 1993. Localization of GABA-like immunoreactivity in the monkey amygdala. Neuroscience 52: $281-294$.

McDonald, A.J. and Betette, R.L. 2001. Parvalbumin-containing neurons in the rat basolateral amygdala: Morphology and co-localization of Calbindin-D(28k). Neuroscience 102: 413-425.

McDonald, A.J. and Mascagni, F. 1997. Projections of the lateral entorhinal cortex to the amygdala: A Phaseolus vulgaris leucoagglutinin study in the rat. Neuroscience 77: 445-459.

McDonald, A.J., Mascagni, F., and Guo, L. 1996. Projections of the medial and lateral prefrontal cortices to the amygdala: A Phaseolus vulgaris leucoagglutinin study in the rat. Neuroscience 71: 55-75.

Milad, M.R. and Quirk, G.J. 2002. Neurons in medial prefrontal cortex signal memory for fear extinction. Nature 420: 70-74.

Milad, M.R., Vidal-Gonzalez, I., and Quirk, G.J. 2004. Electrical stimulation of medial prefrontal cortex reduces conditioned fear in a temporally specific manner. Behav. Neurosci. 118: 389-394.

Miller, E.K. and Cohen, J.D. 2001. An integrative theory of prefrontal cortex function. Ann. Rev. Neurosci. 24: 167-202.

Miserendino, M.J., Sananes, C.B., Melia, K.R., and Davis, M. 1990. Blocking of acquisition but not expression of conditioned fear-potentiated startle by NMDA antagonists in the amygdala. Nature 345: 716-718.

Morgan, M.A. and LeDoux, J.E. 1995. Differential contribution of dorsal and ventral medial prefrontal cortex to the acquisition and extinction of conditioned fear in rats. Behav. Neurosci. 109: 681-688.

Morgan, M.A., Romanski, L.M., and LeDoux, J.E. 1993. Extinction of emotional learning: Contribution of medial prefrontal cortex. Neurosci. Lett. 163: 109-113.

Morgan, M.A., Schulkin, J., and LeDoux, J.E. 2003. Ventral medial prefrontal cortex and emotional perseveration: The memory for prior extinction training. Behav. Brain Res. 146: 121-130.

Morris, R.G. 1989. Synaptic plasticity and learning: Selective impairment of learning rats and blockade of long-term potentiation in vivo by the $N$-methyl-D-aspartate receptor antagonist AP5. J. Neurosci. 9: 3040-3057.

Morrow, B.A., Elsworth, J.D., Rasmusson, A.M., and Roth, R.H. 1999. The role of mesoprefrontal dopamine neurons in the acquisition and expression of conditioned fear in the rat. Neuroscience 92: 553-564.

Muller, N.G., Machado, L., and Knight, R.T. 2002. Contributions of subregions of the prefrontal cortex to working memory: Evidence from brain lesions in humans. J. Cogn. Neurosci. 14: 673-686.

Myers, K.M. and Davis, M. 2002. Behavioral and neural analysis of extinction. Neuron 36: 567-584.

Nader, K., Majidishad, P., Amorapanth, P., and LeDoux, J.E. 2001. Damage to the lateral and central, but not other, amygdaloid nuclei prevents the acquisition of auditory fear conditioning. Learn. Mem. 8: $156-163$.

Nauta, W.J. 1971. The problem of the frontal lobe: A reinterpretation. J. Psychiatric Res. 8: $167-187$.

Owen, A.M., Herrod, N.J., Menon, D.K., Clark, J.C., Downey, S.P., Carpenter, T.A., Minhas, P.S., Turkheimer, F.E., Williams, E.J., Robbins, T.W., et al. 1999. Redefining the functional organization of working memory processes within human lateral prefrontal cortex. Eur. J. Neurosci. 11: 567-574.

Paré, D. 2003. Role of the basolateral amygdala in memory consolidation. Prog. Neurobiol. 70: 409-420.

Paré, D. and Smith, Y. 1993. The intercalated cell masses project to the central and medial nuclei of the amygdala in cats. Neuroscience 57: $1077-1090$.

. 1998. Intrinsic circuitry of the amygdaloid complex: Common principles of organization in rats and cats. Trends Neurosci. 21: 240-241.

Paré, D., Smith, Y., and Paré, J.F. 1995. Intra-amygdaloid projections of the basolateral and basomedial nuclei in the cat: Phaseolus vulgaris-leucoagglutinin anterograde tracing at the light and electron microscopic level. Neuroscience 69: 567-583.

Paré, D., Royer, S., Smith, Y., and Lang, E.J. 2003. Contextual inhibitory gating of impulse traffic in the intra-amygdaloid network. Ann. NY Acad. Sci. 985: 78-91.

Paré, D., Quirk, G.J., and LeDoux, J.E. 2004. New vistas on amygdala networks in conditioned fear. J. Neurophysiol. 92: 1-9.

Paxinos, G. and Watson, C. 1998. The rat brain in stereotaxic coordinates. Academic Press, New York.

Phelps, E.A., Delgado, M., Nearing, K., and LeDoux, J.E. 2004. Extinction learning in humans: Role of the amygdala and vmPFC. Neuron 43: 897-905.

Phillips, R.G. and LeDoux, J.E. 1992. Differential contribution of amygdala and hippocampus to cued and contextual fear conditioning. Behav. Neurosci. 106: 274-285.

Pitkänen, A. 2001. Connectivity of the rat amygdaloid complex. In The amygdala: A functional analysis (ed. J.P. Aggleton), pp. 31-116. Oxford University Press, New York.

Pitkänen, A., Savander, V., and LeDoux, J.E. 1997. Organization of intra-amygdaloid circuitries in the rat: An emerging framework for understanding functions of the amygdala. Trends Neurosci. 20: 517-523.

Pitkänen, A., Jolkkonen, E., and Kemppainen, S. 2000a. Anatomic heterogeneity of the rat amygdaloid complex. Folia Morphol (Warsz) 59: $1-23$.

Pitkänen, A., Pikkarainen, M., Nurminen, N., and Ylinen, A. $2000 \mathrm{~b}$. Reciprocal connections between the amygdala and the hippocampal

\section{Learning \& Memory}


formation, perirhinal cortex, and postrhinal cortex in rat. A review. Ann. NY Acad. Sci. 911: 369-391.

Pitkänen, A., Savander, M., Nurminen, N., and Ylinen, A. 2003. Intrinsic synaptic circuitry of the amygdala. Ann. NY Acad. Sci. 985: 34-49.

Posner, M. 1992. Attention as a cognitive and neural system. Curr. Dir. Psychol. Sci. 1: 11-14.

Povinelli, D.J. and Preuss, T.M. 1995. Theory of mind: Evolutionary history of a cognitive specialization. Trends Neurosci. 18: 418-424.

Preuss, T.M. 1995. Do rats have prefrontal cortex? The

Rose-Woolsey-Akert program reconsidered. J. Cogn. Neurosci. 7: 1-24.

Quirk, G.J. and Gehlert, D.R. 2003. Inhibition of the amygdala: Key to pathological states? Ann. NY Acad. Sci. 985: 263-272.

Quirk, G.J., Repa, C., and LeDoux, J.E. 1995. Fear conditioning enhances short-latency auditory responses of lateral amygdala neurons: Parallel recordings in the freely behaving rat. Neuron 15: 1029-1039.

Quirk, G.J., Russo, G.K., Barron, J.L., and Lebron, K. 2000. The role of ventromedial prefrontal cortex in the recovery of extinguished fear. J. Neurosci. 20: 6225-6231.

Quirk, G.J., Likhtik, E., Pelletier, J.G., and Paré, D. 2003. Stimulation of medial prefrontal cortex decreases the responsiveness of central amygdala output neurons. J. Neurosci. 23: 8800-8807.

Rainnie, D.G. 2003. Inhibitory and excitatory circuitries in amygdala nuclei: A synopsis of session II. Ann. NY Acad. Sci. 985: 59-66.

Repa, J.C., Muller, J., Apergis, J., Desrochers, T.M., Zhou, Y., and LeDoux, J.E. 2001. Two different lateral amygdala cell populations contribute to the initiation and storage of memory. Nat. Neurosci. 4: $724-731$.

Rescorla, R.A. 2001. Retraining of extinguished Pavlovian stimuli. J. Exp. Psychol. Anim. Behav. Process. 27: 115-124.

Robbins, T.W. 1996. Dissociating executive functions of the prefrontal cortex. Philos. Trans. R. Soc. Lond. B Biol. Sci. 351: 1463-1470.

Rodrigues, S.M., Schafe, G.E., and LeDoux, J.E. 2001. Intra-amygdala blockade of the NR2B subunit of the NMDA receptor disrupts the acquisition but not the expression of fear conditioning. J. Neurosci. 21: 6889-6896.

Rogan, M.T., Staubli, U.V., and LeDoux, J.E. 1997. Fear conditioning induces associative long-term potentiation in the amygdala. Nature 390: 604-607.

Rogers, R.D., Owen, A.M., Middleton, H.C., Williams, E.J., Pickard, J.D., Sahakian, B.J., and Robbins, T.W. 1999. Choosing between small, likely rewards and large, unlikely rewards activates inferior and orbital prefrontal cortex. J. Neurosci. 19: 9029-9038.

Rolls, E.T. 1996. The orbitofrontal cortex. Philos. Trans. R. Soc. Lond. B Biol. Sci. 351: 1433-1443.

. 2000. The orbitofrontal cortex and reward. Cereb. Cortex 10: $284-294$.

Room, P., Russchen, F.T., Groenewegen, H.J., and Lohman, A.H. 1985. Efferent connections of the prelimbic (area 32) and the infralimbic (area 25) cortices: An anterograde tracing study in the cat. J. Comp. Neurol. 242: 40-55.

Rosenkranz, J.A. and Grace, A.A. 1999. Modulation of basolateral amygdala neuronal firing and afferent drive by dopamine receptor activation in vivo. J. Neurosci. 19: 11027-11039.

2001. Dopamine attenuates prefrontal cortical suppression of sensory inputs to the basolateral amygdala of rats. J. Neurosci. 21: $4090-4103$.

2002. Cellular mechanisms of infralimbic and prelimbic prefrontal cortical inhibition and dopaminergic modulation of basolateral amygdala neurons in vivo. J. Neurosci. 22: 324-337.

Rosenkranz, J.A., Moore, H., and Grace, A.A. 2003. The prefrontal cortex regulates lateral amygdala neuronal plasticity and responses to previously conditioned stimuli. J. Neurosci. 23: 11054-11064.

Rothbaum, B.O. and Davis, M. 2003. Applying learning principles to the treatment of post-trauma reactions. Ann. NY Acad. Sci. 1008: $112-121$.

Royer, S. and Paré, D. 2002. Bidirectional synaptic plasticity in intercalated amygdala neurons and the extinction of conditioned fear responses. Neuroscience 115: 455-462.

Royer, S., Martina, M., and Paré, D. 1999. An inhibitory interface gates impulse traffic between the input and output stations of the amygdala. J. Neurosci. 19: 10575-10583.

Sah, P., Faber, E.S., Lopez De Armentia, M., and Power, J. 2003. The amygdaloid complex: Anatomy and physiology. Physiol. Rev. 83: $803-834$

Savander, V., Miettinen, R., Ledoux, J.E., and Pitkänen, A. 1997. Lateral nucleus of the rat amygdala is reciprocally connected with basal and accessory basal nuclei: A light and electron microscopic study. Neuroscience 77: 767-781.

Schafe, G.E. and LeDoux, J.E. 2000. Memory consolidation of auditory Pavlovian fear conditioning requires protein synthesis and protein kinase A in the amygdala. J. Neurosci. 20: RC96.

Schafe, G.E., Atkins, C.M., Swank, M.W., Bauer, E.P., Sweatt, J.D., and
LeDoux, J.E. 2000. Activation of ERK/MAP kinase in the amygdala is required for memory consolidation of Pavlovian fear conditioning. $J$. Neurosci. 20: 8177-8187.

Schafe, G.E., Nader, K., Blair, H.T., and LeDoux, J.E. 2001. Memory consolidation of Pavlovian fear conditioning: A cellular and molecular perspective. Trends Neurosci. 24: 540-546.

Seamans, J.K., Floresco, S.B., and Phillips, A.G. 1995. Functional differences between the prelimbic and anterior cingulate regions of the rat prefrontal cortex. Behav. Neurosci. 109: 1063-1073.

Selden, N.R., Everitt, B.J., Jarrard, L.E., and Robbins, T.W. 1991. Complementary roles for the amygdala and hippocampus in aversive conditioning to explicit and contextual cues. Neuroscience 42: $335-350$.

Sesack, S.R., Deutch, A.Y., Roth, R.H., and Bunney, B.S. 1989. Topographical organization of the efferent projections of the medial prefrontal cortex in the rat: An anterograde tract-tracing study with Phaseolus vulgaris leucoagglutinin. J. Comp. Neurol. 290: 213-242.

Shin, L.M., Whalen, P.J., Pitman, R.K., Bush, G., Macklin, M.L., Lasko, N.B., Orr, S.P., McInerney, S.C., and Rauch, S.L. 2001. An fMRI study of anterior cingulate function in posttraumatic stress disorder. Biol. Psychiatry 50: 932-942.

Shinonaga, Y., Takada, M., and Mizuno, N. 1994. Topographic organization of collateral projections from the basolateral amygdaloid nucleus to both the prefrontal cortex and nucleus accumbens in the rat. Neuroscience 58: 389-397.

Shumyatsky, G.P., Tsvetkov, E., Malleret, G., Vronskaya, S., Hatton, M., Hampton, L., Battey, J.F., Dulac, C., Kandel, E.R., and Bolshakov, V.Y. 2002. Identification of a signaling network in lateral nucleus of amygdala important for inhibiting memory specifically related to learned fear. Cell 111: 905-918.

Siegle, G.J., Steinhauer, S.R., Thase, M.E., Stenger, V.A., and Carter, C.S. 2002. Can't shake that feeling: Event-related fMRI assessment of sustained amygdala activity in response to emotional information in depressed individuals. Biol. Psychiatry 51: 693-707.

Siegle, G.J., Konecky, R.O., Thase, M.E., and Carter, C.S. 2003. Relationships between amygdala volume and activity during emotional information processing tasks in depressed and never-depressed individuals: An fMRI investigation. Ann. NY Acad. Sci. 985: $481-484$

Smith, E.E. and Jonides, J. 1999. Storage and executive processes in the frontal lobes. Science 283: 1657-1661.

Smith, Y. and Paré, D. 1994. Intra-amygdaloid projections of the lateral nucleus in the cat: PHA-L anterograde labeling combined with postembedding GABA and glutamate immunocytochemistry. J. Comp. Neurol. 342: 232-248.

Smith, Y., Paré, J.F., and Paré, D. 2000. Differential innervation of parvalbumin-immunoreactive interneurons of the basolateral amygdaloid complex by cortical and intrinsic inputs. J. Comp. Neurol. 416: 496-508.

Sotres-Bayon, F., Bush, D.E.A., and LeDoux, J.E. 2004. Blockade of the NR2B subunit of the NMDA receptor disrupts fear extinction learning. Soc. Neurosci. Abstr. 208.5.

Teich, A.H., McCabe, P.M., Gentile, C.C., Schneiderman, L.S., Winters, R.W., Liskowsky, D.R., and Schneiderman, N. 1989. Auditory cortex lesions prevent the extinction of Pavlovian differential heart rate conditioning to tonal stimuli in rabbits. Brain Res. 480: $210-218$.

Uylings, H.B., Groenewegen, H.J., and Kolb, B. 2003. Do rats have a prefrontal cortex? Behav. Brain Res. 146: 3-17.

van Groen, T. and Wyss, J.M. 1990. Extrinsic projections from area CA1 of the rat hippocampus: Olfactory, cortical, subcortical, and bilateral hippocampal formation projections. J. Comp. Neurol. 302: 515-528.

Vertes, R.P. 2004. Differential projections of the infralimbic and prelimbic cortex in the rat. Synapse 51: 32-58.

Walker, D.L. and Davis, M. 2000. Involvement of NMDA receptors within the amygdala in short- versus long-term memory for fear conditioning as assessed with fear-potentiated startle. Behav. Neurosci. 114: 1019-1033.

. 2002. The role of amygdala glutamate receptors in fear learning, fear-potentiated startle, and extinction. Pharmacol. Biochem. Behav. 71: $379-392$.

Walker, D.L., Ressler, K.J., Lu, K.T., and Davis, M. 2002. Facilitation of conditioned fear extinction by systemic administration or intra-amygdala infusions of D-cycloserine as assessed with fear-potentiated startle in rats. J. Neurosci. 22: 2343-2351.

Weisskopf, M.G., Bauer, E.P., and LeDoux, J.E. 1999. L-type voltage-gated calcium channels mediate NMDA-independent associative long-term potentiation at thalamic input synapses to the amygdala. J. Neurosci. 19: 10512-10519.

Wilson, A., Brooks, D.C., and Bouton, M.E. 1995. The role of the rat hippocampal system in several effects of context in extinction. Behav. Neurosci. 109: 828-836. 


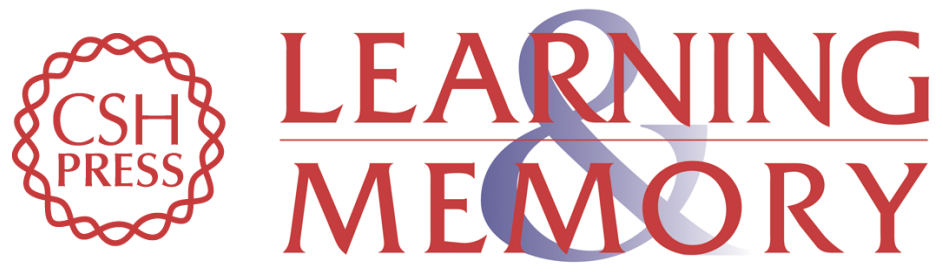

\section{Emotional Perseveration: An Update on Prefrontal-Amygdala Interactions in Fear Extinction}

Francisco Sotres-Bayon, David E.A. Bush and Joseph E. LeDoux

Learn. Mem. 2004, 11:

Access the most recent version at doi:10.1101/lm.79504

References This article cites 167 articles, 39 of which can be accessed free at: http://learnmem.cshlp.org/content/11/5/525.full.html\#ref-list-1

License

Email Alerting Receive free email alerts when new articles cite this article - sign up in the box at the Service top right corner of the article or click here. 